\title{
PERSONA ÉTICA Y ORGANIZACIÓN: Hacia un nuevo paradigma organizacional ${ }^{*}$
}

\author{
Alfredo Rodríguez \\ UNIVERSIDAD DE NAVARRA (ESPAÑA) \\ arsedano@unav.es \\ Juan Carlos Aguilera \\ UNIVERSIDAD ADOLFO IBÁÑEZ (CHILE) \\ juan.aguilera@uai.cl
}

\section{Resumen}

La importancia de la ética en la empresa muchas veces no pasa de las buenas intenciones. El filósofo Josef Pieper alertó sobre esta situación al escribir acerca de la prudencia, virtud que está en la base del trabajo directivo y, por consiguiente, de la ética en la empresa y la llamada responsabilidad social corporativa o empresarial, que no está exenta del problema pues existen diferentes formas de entender su significado. Sin embargo, antes de cualquier consideración sobre la importancia de la relación empresa-sociedad, o los valores y la acción moral en las organizaciones, conviene tener en cuenta que el tipo de organización depende de la idea de persona que se tenga. Sin una visión antropológica no es posible acercarse al cómo actúan las personas en las organizaciones y los fines de la misma. Nuestro trabajo intenta contribuir con una propuesta en la que la organización se explica desde la persona y se ordena a partir de ella.

Palabras clave: ética empresarial, teoría de la organización, cultura organizacional, comportamiento organizacional, enfoque antropológico.

\begin{abstract}
In many corporations, the importance of ethics does not go further than just good intentions. Philosopher Josef Pieper warned about this situation when he wrote about prudence, a virtue that is at the basis of outstanding management and thus, also of company ethics and corporate social responsibility, an issue included in the problem as there are many ways to understand its significance. However, before any consideration on the importance of company-social relationships or on the values and moral actions of organizations, we must bear in mind that the type of corporation depends on the type of individual we represent in our minds. Without an anthropological vision it is not possible to ascertain the actions of people in the corporation or their attitudes towards its goals. Our work will try to contribute a proposal in which the corporation is explained and organized from the point of view of the people.
\end{abstract}

Key words: corporate ethics, corporate theory, corporate culture, corporate behaviour, anthropolical approach.

* Este trabajo es una versión revisada del publicado en los Anales del VIII Congreso de la Asociación Latinoamericana de Ética, Negocios y Economía (Alene), llevado a cabo el 11 y 12 de agosto de 2005 en Valparaíso, Chile. 
$E^{n}$ estos tiempos, es difícil dejar de reconocer que la persona ha ido adquiriendo mayor importancia en las organizaciones dentro del contexto de la llamada sociedad del conocimiento. La aparición de diversos conceptos como capital social, gestión del talento, liderazgo estratégico, trabajador del conocimiento y responsabilidad social corporativa, entre otros, es una expresión cabal de esa importancia. Sin embargo, frente a la valorización teórica de la persona, aparecen de modo preocupante mayores índices de insatisfacción laboral, estrés, ausentismo laboral, dificultades para armonizar trabajo y familia, etcétera. Todos estos aspectos son manifestaciones que, en cierto sentido, contradicen la preocupación acerca de la persona en la organización.

La llamada gerencia de personas, que reemplaza a la gerencia de recursos humanos, constituye un gran avance, al menos nominalmente. Aunque, como nos recordaba Alejandro Llano, fue el gran Homero quien muchos siglos atrás afirmaba que el hombre es un ser fértil en recursos (o en términos de un economista ya clásico, el hombre es la verdadera riqueza de las naciones). Es decir, autor y protagonista de sus acciones al interior de las organizaciones que en el último siglo han sido decisivas en la configuración de nuevas realidades, como señaló Peter Drücker. Una de esas nuevas realidades son las organizaciones empresariales que, por haber sido fundadas y estar formadas por personas, pueden ser denominadas justamente organizaciones inteligentes. Por tanto, es relevante, desde una determinada perspectiva, intentar hacer notar el progreso que se ha dado a lo largo del tiempo en el modo de enfocar la organización, pero al mismo tiempo advertir la insuficiencia de los diversos estudios propuestos y la necesidad de plantear uno nuevo que ayude a comprender mejor su constitución y la actividad que llevan a cabo las personas en ella. El hilo conductor de este análisis es el concepto de ética, y la reflexión clave es cómo se le percibe espiritualmente en la organización.

La razón que fundamenta esta pregunta es que si el objeto material de la ciencia ética reside en la acción humana, es fácilmente comprensible que toda propuesta ética debe tener como sustento un modelo básico de hombre y, sobre todo, de su forma de comportarse y tomar decisiones. Por eso, analizada la acción humana en los diversos enfoques, se sugiere uno nuevo cuya característica fundamental es no ser restrictivo en el modo de abordar la acción y, consecuentemente, la ética. Dicho de otro modo, una organización que pueda dar respuesta a tantas interrogantes a las que la teoría general de sistemas, a pesar de sus grandes logros, se ve impedida de hacerlo.

Para desarrollar este trabajo nos basaremos en el esquema propuesto por Pérez López (1994) que nos permite establecer un modelo alternativo en la teoría de la organización, el cual se fundamenta en la estructura psíquica de la persona humana. Esto supondrá introducir unas variables nuevas -concretamente aristotélicasrespecto a los postulados neokantianos que se encuentran en las otras alternativas que presentaremos. Por la amplitud del trabajo, no nos será posible una plena justificación de estas nuevas variables, aunque permitirán dejar abiertas las puertas para futuras investigaciones en esta dirección.

En este contexto general, se presentan claramente dos alternativas en el proce- 
dimiento que debemos seguir: superar los planteamientos actuales de la teoría de la organización desde ellos mismos, o bien, una vez mostrada su insuficiencia, plantear opciones que induzcan a una nueva dirección en la búsqueda de un paradigma básico que interprete adecuadamente la organización y las exigencias del individuo en ella.

De acuerdo con Maclntyre (1992: 151-152), la superación de un paradigma no se puede hacer desde dentro, si se trata de abandonar algunos supuestos básicos del paradigma. Hace falta, pues, «alguien que viva en ambos esquemas conceptuales alternativos, que conozca y sea capaz de hablar el lenguaje de cada uno desde dentro, que haya llegado a ser, por decirlo así, un hablante nativo con dos lenguas primeras». Por esta razón el presente trabajo tiene una perspectiva interdisciplinaria. Somos conscientes, y ese es nuestro propósito, de que establecer un diálogo entre las ciencias permite una mejor comprensión de los fenómenos que se estudian, bien sean económicos, sociales u organizacionales.

En este sentido, la tarea que nos proponemos se orienta en la línea de lo que Pérez López señaló en un acto académico en la Universidad de Navarra, de España:

Lo que hay de valioso en la ciencia actual ha de ser subsumido, como tal caso particular que es, en la nueva ciencia. No olvidemos que el gran error de todas las metodologías en boga es su reduccionismo -las abstracciones incompletas en las que se fundan-, pero que todos los reduccionismos son verdaderos en lo que afirman -de ahí su vigencia práctica-y falsos en lo que niegan. Todo lo que hemos aprendido acerca de los fenómenos empíricos, que es mucho, está clamando por ser correctamente explicado.

Esto es, en definitiva, lo que se pretende con la propuesta del enfoque antropológico que tratamos de llevar a cabo.

Para afrontar el análisis, siguiendo un esquema paralelo al desarrollado por Pérez López, vamos a partir de la consideración de tres grandes grupos de teorías o modelos -paradigmas-que permiten explicar el funcionamiento de las organizaciones. El primero explica la organización y su comportamiento asimilándola a una gran maquinaria; la interpreta, pues, como un gran sistema técnico. A quienes han entendido así el comportamiento de las empresas los incluiremos dentro de los enfoques mecanicistas. En segundo lugar, nos referiremos a aquellos para quienes la organización es comparable a un organismo vivo, en constante movimiento y en continua interacción con su entorno. Hablaremos entonces de los enfoques organicistas o psico-sociológicos, por cuanto insertan variables no estrictamente técnicas. Para terminar, centraremos la atención en aquellos enfoques que consideran la organización como algo más que un sistema técnico o sociopolítico. En estos puntos de vista se incluyen todas aquellas teorías que entienden la organización como una institución de personas, como una comunidad que comparte unos objetivos: son los enfoques antropológicos.

Este modo de clasificar las distintas interpretaciones de la organización y su funcionamiento nos parece muy útil por su poder explicativo, contando con las inevitables limitaciones propias de toda analogía. El esquema permite recoger de modo muy simplificado los rasgos básicos que subyacen en gran parte de las 
interpretaciones teóricas, por lo cual es evidente que los matices de las diversas concepciones no podrán ser analizados en el presente estudio. La finalidad de este trabajo es sugerir un nuevo enfoque organizacional basado en la reflexión acerca del papel que cumple la ética en la dirección de empresas a través de la conducta de la persona en la organización. Un análisis de los fundamentos que sustentan los principales enfoques organizativos nos permitirá obtener conclusiones relacionadas con la dimensión ética y su cabida en las teorías de la organización y, por consiguiente, reconocer la teoría de la acción que existe en esos enfoques.

\section{Los enfoques mecanicistas}

Estas teorías contemplan la organización «como una simple coordinación de acciones humanas cuya finalidad es la de producir y distribuir una serie de objetos y/o servicios» (Pérez López, 1994: 22). Se centran en la vertiente objetiva de la actuación empresarial ignorando la subjetiva, es decir, el impacto que este obrar tiene sobre el sujeto que las realiza. Se trata, pues, de organizar los procesos y el intercambio de productos. No hay especial interés por considerar que los implicados en esos procesos son personas; estas son un elemento más de la compleja maquinaria. En este sentido, «no quedan recogidos ni los motivos de las personas, ni sus necesidades, ni las interacciones que no estén incluidas en el sistema productivo-distributivo» (Pérez López, 1994:22).

Para quienes inicialmente entendieron así la organización, el hombre de empresa se distinguía por su dureza y su estilo de dirección. Se apoyaba en pasar por encima de sus sentimientos personales y de los demás, en aras de un mejor logro de los beneficios (Taylor, 1911; Fayol, 1949). Lo verdaderamente importante es la maximización de la relación producción-consumo, bien sea optimizando la producción o minimizando los recursos en orden a una producción, o simplemente maximizando la diferencia entre la relación propuesta.

La deficiencia de este enfoque hay que verla en la parcialidad con que trata el trabajo. Ciertamente, hay una dimensión objetiva del trabajo que hace referencia a lo que la persona produce $\mathrm{y}$, en este sentido, es correcto hablar del trabajo como factor de producción y es lícito valorar este factor de acuerdo con las reglas de mercado. Pero no hay que olvidar la dimensión subjetiva que el trabajo conlleva, derivada del hecho de que quien lo ejecuta es una persona, señalando que las fuentes de la dignidad del trabajo deben buscarse principalmente no en su dimensión objetiva, sino en su dimensión subjetiva, porque el primer fundamento del valor del trabajo es el hombre mismo. En estos enfoques no hay finalidad compartida, los motivos de las personas quedan ignorados, la libertad y participación están en la penumbra.

No obstante, gracias a las abstracciones que implica este modelo se han logrado grandes avances en el desarrollo de técnicas para mejorar la productividad y la rentabilidad en las empresas. El propósito de la organización, entendido en sentido estrictamente económico, ha podido especificarse mediante la denominada planificación estratégica, que conjuga las capacidades del sistema con la situación del entorno empresarial. Se trata, pues, de conseguir los mayores resultados posibles al menor costo. 
La parcialidad de estos enfoques se encuentra en el modo de concebir el trabajo como ajeno a la dignidad de la persona que lo realiza. Así, el modelo de persona con el que elaboran estos enfoques es, en realidad, bastante reducido, al quedarse en la dimensión objetiva del trabajo. La preocupación medular no son las personas concretas, sino los papeles y funciones que estas interpretan, así como las relaciones de comunicación que entre ellas se establecen. La organización informal suele quedar fuera de su campo de análisis. La racionalidad de los que toman decisiones en la organización, por reducir sus propósitos a la maximización del beneficio, puede ser calificada como racionalidad instrumental: todo es interpretado en clave de medio o instrumento para el logro de resultados. Los bienes útiles pierden su carácter de medio y se convierten en fines de la acción humana. Para entender cabalmente la organización y el trabajo en estos enfoques, quizás sería oportuno recordar las consecuencias que Schumpeter (1971) y Weber (1995) extrajeron del análisis del espíritu capitalista en la racionalidad del empresario (Rodríguez, 1999a y 1999b).

Tomando en cuenta las causas que originan este modo de actuar, las motivaciones de los individuos sólo se consideran al hablar de los sistemas retributivos, que son medios para la distribución de los incentivos. En el fondo las motivaciones de la persona quedan reducidas a la búsqueda de recompensas externas (aumento salarial, comisión, mejora del estatus), que Pérez López (1997: 18) denomina necesidades extrínsecas.

En realidad, la mayor parte de los textos especializados en dirección de empresas ha estado enmarcada dentro de este paradigma. De modo especialmente claro pueden apreciarse los frutos que hemos resaltado en las primeras propuestas del management científico, así como en los comienzos de la planificación estratégica. Cualquier directivo es consciente de que estos enfoques pueden ser útiles en su sentido técnico, pero sería aventurado afirmar que las decisiones directivas son exclusivamente técnicas. Son muchos los que a diario intentan realizar cambios técnicos y se enfrentan, sin embargo, a la resistencia de las personas en la organización. Intentar reducir todo a este plano es, cuando menos, poco realista.

Las preguntas que surgen, y que nos llevaron a plantear este análisis, son: ¿Qué lugar puede ocupar la ética en estas concepciones de la organización? ¿Tiene sentido hablar de ética bajo estos parámetros de interpretación de la realidad empresarial? Como se ha visto, el individuo es reducido a una pieza del sistema, sus motivaciones son exclusivamente extrínsecas, los valores por los que se mueve han sido reducidos al plano económico o instrumental, y las normas que rigen su comportamiento vienen marcadas por la función que desempeña en la organización. Por consiguiente, las relaciones personales quedan reducidas al cumplimiento de roles o funciones con el propósito de alcanzar la máxima eficacia. Para ello la organización tiene como mecanismo motivador un sistema de premios y castigos. Una ética utilitarista (Bentham, 1973; Sen, 1979), de mero cálculo, preocupada exclusivamente por el beneficio, o una ética pragmática que toma en cuenta sólo los resultados, parecen ser los únicos enfoques morales que cabría considerar en este modo de interpretar las organizaciones. Es pertinente hablar de una ética individualista coincidente con la ética que 
Weber (1944 y 1995) descubre en el capitalismo. Un desarrollo más exhaustivo de estas dos cuestiones, en las que se lleva a cabo un análisis pormenorizado de las diversas formas de entender la ética y la acción de la ética en la teoría de la organización, puede verse en Fontrodona, Guillén y Rodríguez (1998).

Con estos supuestos el planteamiento mecanicista requiere, entonces, un tipo de individuo que cumpla al pie de la letra las tareas que se le encomiendan; que se limite a obedecer ciegamente lo que se le manda, generando una actitud reactiva ante el trabajo, cuya máxima podría ser: «debo hacer lo que me digan y cuando me lo digan». Su incapacidad para tomar decisiones y asumir riesgos lo conduce a cumplir con lo mínimo requerido, para que no le puedan decir nada. La negatividad y el centrarse exclusivamente en los errores generan una dependencia que busca seguridad a costa de la capacidad creativa, característica singular de la persona como expresión de la libertad. La desmoralización del sujeto convertido en funcionario origina la idea de que el trabajo es una carga insoportable, al igual que quienes pertenecen a la organización.
El modelo de hombre egoísta, en busca de su exclusivo beneficio particular, propugna una forma de entender la ética en la organización cuyos juicios se reducen a la obtención de la mayor utilidad individual posible. En un sistema en el que la prioridad es la maximización de los beneficios, dejando a un lado la posible mejora personal de quienes los producen, la formulación ética es tremendamente limitada, carente de fundamento y poco rigurosa. Viene a coincidir, sustancialmente, con el ethos que expresan las máximas ético-económicas.

Con tal perspectiva la organización carece de la capacidad de anticiparse a los cambios del entorno; y desaprovecha el talento de sus miembros al exigir el mero cumplimiento de normas, bajo la mirada atenta del directivo que busca resultados a corto plazo, sin importarle muchas veces los medios que se utilicen para conseguir el objetivo. De este modo, la organización expone su viabilidad y proyección. En este escenario la creatividad y el aporte de la persona, un mero objeto, no son necesarios.

\section{Enfoques mecanicistas}

\begin{tabular}{lll}
\hline Modelo de organización & Máquina & Económico \\
& Propósito & \\
\hline Concepto de persona & Objeto & \\
& Racionalidad & Instrumental \\
& Motivaciones & Extrínsecas \\
& Valores & Económicos \\
& Normas & Funcionales \\
\hline Enfoque ético & Enfoques unilaterales & Normativismo \\
& & Utilitarismo \\
& & Pragmatismo \\
\hline
\end{tabular}




\section{Los enfoques psico-sociológicos}

Frente a la orientación hacia los resultados -el trabajo en sentido objetivo- que reivindican las ciencias económicas y de la empresa en sus orígenes, surgen otros modelos a partir del estudio del comportamiento de quien es el sujeto de la producción. Intuyen estos enfoques la dimensión subjetiva del trabajo pero no acaban de formularla. De este modo, no abandonan el supuesto de la maximización relación-producción, pero abogan por hacer más hincapié en el sujeto productor; así será posible lograr una mayor y mejor producción, al tiempo que se satisfacen unas necesidades que contribuyen a optimizar los resultados. La aparición de las relaciones humanas (Mayo, 1946; Roethlisberger y Dickson, 1939), un nuevo fenómeno social en la empresa, presenta ahora a un empresario de rasgos menos autoritarios. El concepto de hombre-máquina-recurso se suaviza, y se trata de buscar una mayor satisfacción del hombre en el trabajo, enriquecer su tarea, mejorar las condiciones laborales, respeto en el trato, etcétera.

La analogía más adecuada para entender este nuevo paradigma es la de un organismo vivo. Todo aquello que dijeron los enfoques anteriores es ahora asumido por el nuevo paradigma. A él se incorporan nuevas dimensiones y un nuevo modo de entender las relaciones entre los elementos del sistema. Quizá lo más característico de este enfoque es su actitud proactiva ante el entorno y el carácter funcional (Weber, 1947) que se trata de inscribir en la empresa: las organizaciones solicitan especialistas.

Apoyándose en el carácter funcional, la empresa promueve un giro hacia la des- centralización (McGregor, 1960; Likert, 1961 y 1967; Hax and Majluf, 1984) como base para una mayor optimización de los recursos disponibles. Se introducen una serie de conceptos que adquieren fuerza en el ámbito empresarial: cooperación, participación... Estos conceptos son necesarios y básicos para que la descentralización se lleve a cabo sin merma de la productividad. Las decisiones se implantan en todos los niveles posibles (March y Simon, 1958; Simon, 1979; Cyert and March, 1963), necesitando de estos conceptos para no perder de vista el fin prioritario de la empresa. A partir de los años setenta, la participación se convierte en el leitmotiv de buena parte de organizaciones empresariales. El estudio de las motivaciones, que ya venía siendo objeto de investigación (Maslow, 1954; Herzberg, 1966; Herzberg, Mausner and Snydennan, 1959; McGregor, 1966), ocupa un lugar prioritario.

En este enfoque las motivaciones humanas no se interpretan exclusivamente en clave externa (búsqueda de recompensas), se admite ahora que son mucho más complejas y que, por tanto, no basta con ofrecer incentivos. Se reconoce que existen motivaciones procedentes del propio actor, satisfacciones que este logra por realizar determinadas acciones y que no provienen de fuera. Son las denominadas motivaciones intrínsecas. Así, el aprendizaje del propio decisor o su realización personal se convierten en elementos clave para explicar los comportamientos en las organizaciones. Una explicación que permite entender «la coordinación de acciones para la satisfacción de motivaciones actuales, es decir, de las motivaciones que actualmente sienten las personas que componen la organización» (Pérez López, 1997: 24). Las motivaciones actuales se 
refieren, en terminología aristotélica, a los bienes deleitables, pero no aseguran que, a su vez, estos remitan a bienes honestos y, por tanto, se quedan en el plano de la mera satisfacción sensible. El análisis de la motivación se efectúa en el plano subjetivo del obrar.

La inclusión en este nuevo paradigma de otras satisfacciones actuales reivindica todo un nuevo modo de hacer empresarial. Se descubren una serie de aspectos que no son ajenos a la organización en la medida en que lo son a las personas y que se deben tener presentes. En una concepción de la empresa entendida como organismo social, las variables psico-sociológicas pasan a ocupar un papel relevante, y la dimensión económica pierde su exclusividad. La mayor parte de las teorías que han pretendido superar el modelo clásico mecanicista se ha movido en una concepción organicista de la persona y de las organizaciones.

En este nuevo paso que suponen los enfoques psico-sociológicos la persona ya no es sólo una pieza de la maquinaria productiva. Sus motivaciones van más allá de la espera de recompensas o castigos. Su racionalidad no es exclusivamente instrumental, optimizadora de resultados. Cabría hablar ahora de una racionalidad expresiva, que reconoce al individuo como dotado de libertad y voluntad. Los juicios de valor comienzan a ser considerados en la toma de decisiones, y los fines del decisor no son exclusivamente económicos. Los valores que comienzan a ser considerados hacen referencia a satisfacciones actuales no estrictamente económicas. Las normas no vienen marcadas exclusivamente por la posición, sino que se interpretan en términos conductuales $\mathrm{y}$ han sido influenciadas por elementos sociales y culturales. Este modo de proceder es coherente con la forma como Weber (1944) entiende la ciencia económica. Ciertamente en los enfoques psicosociológicos se recalca el carácter de la ciencia. Esto se puede observar bien cuando es la decisión la que en última instancia impide el conflicto que puede originarse entre lo que es y lo que debe hacerse. El conflicto se resuelve en la interpretación valorativa que dé el sujeto. De aquí que la valoración -los juicios de valor- sea esencialmente decisional. Las elecciones últimas no se apoyan en los resultados que la ciencia pueda proporcio-

\section{Enfoques psico-sociológicos}

\begin{tabular}{lll}
\hline Modelo de organización & $\begin{array}{l}\text { Organismo social } \\
\text { Propósito }\end{array}$ & $\begin{array}{l}\text { Económico } \\
\text { Social }\end{array}$ \\
\hline Concepto de persona & $\begin{array}{l}\text { Sujeto-individuo } \\
\text { Racionalidad } \\
\text { Motivaciones } \\
\text { Valores }\end{array}$ & $\begin{array}{l}\text { Expresiva } \\
\text { Extrínsecas e intrínsecas }\end{array}$ \\
& Normas & $\begin{array}{l}\text { De satisfacción actual } \\
\text { Conductas y culturales }\end{array}$ \\
& Posturas intermedias & Dialógica \\
& & De justicia social \\
& & Consecuencialista \\
& & Comunitarista \\
\hline
\end{tabular}


nar: proceden de la propia decisión del individuo orientada por los intereses, elementos sociales y culturales.

La cuestión de la responsabilidad social adquiere un fuerte protagonismo en una concepción de la organización que busca dar respuesta al entorno en que se desarrolla (Lawrence y Lorsch, 1967; Lorsch y Allen, 1973; Galbraith, 1973; Chandler, 1962). Con este concepto se pretende, a su vez, eliminar las injustas pretensiones de una economía basada en el exclusivo interés personal. Frente a una concepción de las acciones de los individuos en términos de elección individual, que tiene su raíz en la teoría moral kantiana trasladada a la empresa por el individualismo metodológico, French aboga por un tratamiento en el ámbito de la empresa de lo que Durkheim (1984) ha venido a llamar «hechos sociales». Sin embargo, los orígenes de esta responsabilidad, situada entre los años cincuenta y sesenta y que se prolonga hasta nuestros días, se encuentran en realidad, como señala Mele (1997), en que muchos directivos están convencidos de que esas responsabilidades sociales son una cuestión de egoísmo ilustrado porque, a largo plazo, son ventajosas para quienes las tienen en cuenta. Su punto de referencia son los objetivos y valores de la sociedad. Las demandas que reciben las empresas les exigen una responsabilidad en su cumplimiento. No obstante, la preocupación por la responsabilidad social de la empresa remite a una cuestión, aún no cerrada, que ha dado origen a numerosas interpretaciones acerca de si la responsabilidad es corporativa o más bien de los directivos.

Otros trabajos han añadido distintos matices que enriquecen el modelo básico de la responsabilidad social. Destacan la teoría de la evolución, representada por Nelson y Winter (1982); la escuela ecologista sustentada por Hannan y Freeman (1989), las configuraciones de organizaciones de Mintzberg (1979) y los trabajos de Miller y Friesen (1984) y Miller (1990). Un estudio acerca de la naturaleza de la responsabilidad social de las empresas, que merece especial interés, ha sido desarrollado por Robertson y Nicholson (1996).

El surgimiento de la responsabilidad social hace pensar que la ética no puede considerarse como algo ajeno al ser empresarial, sino que, por el contrario, las empresas necesitan directivos con una adecuada formación ética. Sin embargo, en no pocas ocasiones se reduce la ética a un medio para eliminar las injustas agresiones a las que se ve sometido el individuo en el entorno social.

La ética de la justicia de Rawls (1971) tiene especial cabida en un planteamiento empresarial en el que lo moral es entendido como restricción externa al logro de objetivos económicos. Pero tanto en la ética de la justicia como en la de las éticas dialógica (Cortina, 1994 y 1995 ) y consecuencialista (Anscombe, 1958 y 1981) se corre el riesgo de caer en un minimalismo ético que fácilmente acaba confundiéndose con la mera legalidad. No es extraño que en estas situaciones los directivos crean que la ética es la redacción de un código de conducta de la empresa, en el que se describe el comportamiento moral de las personas de la organización.

Frente a estas posturas, el comunitarismo (Etzioni, 1995) podría presentarse como una alternativa. Aunque se trata de un enfoque crítico al liberalismo, en el que se subraya que no somos individuos 
independientes que acuerdan convivir estableciendo pactos políticos y económicos basados en el interés, las soluciones que aporta no proceden propiamente de instancias éticas, como ya quedara de manifiesto, sino que se trata más bien de un lenguaje moral, con una fuerte carga emotiva. Esto hace que tampoco pueda ser tenido como alternativa válida.

Tanto el modelo técnico como el orgánico, en sus diversas manifestaciones, no suponen una alternativa respecto de la cuestión de la primacía del ser individual sobre el ser social o viceversa (Koslowski, 1983). Esta disyuntiva no parece que pueda ser resuelta acudiendo a procedimientos técnicos o analizando sistemas sociales. Mientras no se recupere el estudio de lo que la persona es, y su papel en la sociedad y en las organizaciones, parece difícil que lleguemos a encontrar respuestas adecuadas a la pregunta por el lugar de la ética. La verdadera solución pasa por advertir que toda técnica socioeconómica tiene, en el fondo, una doctrina antropológica: «la respuesta al ¿qué hacemos? ha de darse con el ¿qué somos?» (Llano, 1991: 44).

No se puede dejar de reconocer que el modelo organicista nos sitúa ante una visión más completa de la realidad. Sin embargo, uno de los peligros que encierra dicho modelo, no mencionado hasta ahora, consiste en el fomento de la competencia interna hasta niveles que pueden derivar en un individualismo exacerbado de los miembros de la organización: centrados únicamente en alcanzar logros y satisfacciones individuales. Resulta paradójico advertir que la competencia interna no es condición necesaria ni suficiente para alcanzar mejores estándares individuales de productividad en la empresa, porque aunque la persona lo haya hecho muy bien, si los demás lo han hecho mejor, significa que lo ha hecho mal. Es decir, se genera un ambiente de mediocridad, en virtud de que el objetivo es más fácilmente alcanzable si se consigue que los demás lo hagan peor, con las consecuencias que ello implica. Y aunque los directivos de la organización, si bien confían en la capacidad profesional de los especialistas dándoles mayor libertad de movimiento, ante el primer endurecimiento del entorno, la política de tomar en cuenta a los individuos se echa por la borda, y queda la impresión de que en realidad nunca se creyó en la gente y sus capacidades. El asunto no pasa de ser una mera manipulación con el propósito de lograr los resultados esperados.

\section{Los enfoques antropológicos}

El estudio de lo que la persona representa en las organizaciones y lo que estas representan para las personas abre las puertas a un nuevo paradigma. Al hablar de enfoques antropológicos nos referimos a aquellos que conciben la organización como una institución que lleva a cabo «la coordinación de acciones de personas para la satisfacción de necesidades reales de los miembros de la organización» (Pérez López, 1994: 28). Es decir, de aquellas necesidades que contribuyen a la perfección del ser humano, y hacen referencia, por tanto, a los bienes honestos, en terminología aristotélica. Este nuevo enfoque de la organización integra los otros dos modelos previamente descritos -mecánico y orgánico-, pero con una diferencia esencial: la técnica es entendida como ciencia subordinada al fin de la persona, sin que por ello pierda el protagonismo que le es esencial en orden 
al logro de los objetivos. Como afirma Polo (1993: 135):

... si la acción humana se impone sobre el objeto técnico, puede alcanzar su finalidad; pero si el objeto técnico, por su magnitud, se impone sobre la acción humana, el hombre no puede asumir su finalidad y queda subordinado a la manera de ser de la técnica.

Dicho de otro modo, si la organización empresarial es de personas, entonces la organización ha de ser el cauce a través del cual el individuo alcance su propio fin y no sólo la satisfacción de unas necesidades actuales. El enfoque antropológico especifica, respecto a los planteamientos anteriores, la dimensión subjetiva del trabajo, sin obviar su dimensión objetiva. De esta forma se logra integrar en un esquema más completo de la acción humana los valiosos aportes que se han venido haciendo de la organización.

Si el enfoque técnico se centraba en «qué» cosas se hacen en la organización, y el enfoque orgánico se centraba no sólo en el «qué» sino también en el «cómo», la nueva propuesta que entiende la organización como institución incorpora a estos dos planos la cuestión del «para qué» se hacen las cosas. Se preocupa también por dar sentido a las acciones que coordina, de ahí que lo característico de la institución sea la consideración de los valores, los principios y los fines que la mueven. La centralidad de la acción humana, la búsqueda de un sentido a las acciones y la asunción del carácter incondicional y objetivo de los valores, está en la base de este nuevo enfoque. Se supera así el dualismo imperante a lo largo de este siglo y se asumen las valiosas contribuciones que se han hecho, eliminando el carácter sub- jetivo y autónomo que las sustenta. Se desarrolla un nuevo concepto de necesidad, basado en el bien honesto, y se incorporan criterios objetivos de satisfacción de necesidades reales en orden a la perfección del bien humano. Este punto supone entender de modo distinto la utilidad y el servicio como actividad primaria de la empresa y el empresario, encauzados ambos a la satisfacción de necesidades humanas (Rodríguez y López de Pedro, 1998).

Coherente con este enfoque, si los objetivos de la empresa son iluminados por los principios que sustentan a la organización, se establece una conexión entre el fin propio de la empresa y de la persona, en el que ambos necesariamente han de armonizarse. La característica que se reconoce en este nuevo modelo es la integración. Se trata de enfocar el fin de la empresa-los objetivos- de acuerdo con los valores y principios que la sustentan. En este enfoque la ética está presente de modo natural, pues en ella precisamente se integran ambas finalidades -la organizativa y la personal-, y hace plausible la armonización de ambas pretensiones, pues es imposible, o al menos no es fácil, hacer el bien cuando se carece de recursos.

Al analizar el modelo de persona que subyace bajo el nuevo paradigma entran en escena dimensiones de la realidad que antes no habían sido consideradas. Los conceptos de racionalidad instrumental y expresiva referidos anteriormente ya no son suficientes. Estos modos de entender la racionalidad olvidan las repercusiones que las decisiones tienen sobre aquellos que las toman. El concepto mismo de «decisión» parece haber llevado a olvidar la repercusión práctica, real, que toda decisión tiene sobre el que actúa. Al actuar, 
el directivo no sólo decide sino que «se decide», se ve implicado en las consecuencias del juicio que ha emitido. Surge así la necesidad de considerar la responsabilidad personal de toda decisión libre como un elemento eminentemente ético.

Otro elemento que incorpora el nuevo paradigma es la consideración de motivaciones que van más allá de las estrictamente actuales. En este sentido, existen motivaciones que no han sido consideradas ni explicadas por los enfoques analizados: es el caso de las motivaciones que se dirigen a satisfacer necesidades de personas distintas a las que realizan la acción. El espíritu de servicio o el de cooperación desinteresada estarían incluidos entre estas motivaciones. No hemos encontrado referencia alguna a ellas en los textos sobre dirección de empresas.

El objetivo de este nuevo enfoque es superar el tinte individualista, así como las tesis deterministas que encierra la teoría organicista. El modelo antropológico hace notar la distinción clásica y no separación entre las realidades materiales y las realidades espirituales, así como la superioridad de estas últimas sobre aquellas, sin que por ello se vea alterada la unidad del ser humano. Es importante este matiz para entender que las satisfacciones reales que propugna el modelo antropológico van más allá de las tendencias sensibles expresadas por los bienes deleitables, y remiten a los bienes honestos, de modo que su «deber-ser» no viene impuesto por la inmediatez que caracteriza las facultades inferiores del hombre, sino por los fines de las facultades superiores.

Las teorías de la motivación que se encuadran en los modelos psico-sociológicos ponen un mayor énfasis en la satis- facción de las necesidades. Por ejemplo, Maslow (1991: 147) señala una jerarquía de necesidades, pero considera que hasta que las necesidades inferiores no están satisfechas no se puede ascender hacia las necesidades superiores, las cuales tienen «menor habilidad para dominar, organizar y someter a su servicio las reacciones automáticas de la persona». El modelo antropológico, en cambio, presenta una visión opuesta a la ofrecida por Maslow. Por una parte, corresponde a las facultades superiores una función rectora respecto a las inferiores; por otra, se presta una mayor atención al dominio de las necesidades que a su satisfacción, de modo que, aunque es necesario que se dé un mínimo de satisfacción de todas ellas, la persona puede sacrificar las necesidades inferiores por las superiores. Este dinamismo es impensable en la teoría de Maslow, puesto que requiere, para ser entendido, una correcta comprensión de las facultades del hombre, y del papel que juegan las virtudes en la acción humana.

En cuanto a los valores, pasan ahora a ser considerados no sólo los referidos a las satisfacciones actuales, sino también todos aquellos que contribuyen al desarrollo personal, así como los que tienen relación con la apertura a los demás. Esta última pone de relieve una muy acertada distinción entre dos tendencias existentes en el hombre, ya clásicamente advertidas: el deseo de tener y la capacidad de compartir. El deseo de tener hace referencia al «ganar», mientras que la capacidad de compartir hace referencia al «servir». $\mathrm{Si}$ se incide sólo en el deseo de tener y se acalla la segunda tendencia, se olvida entonces que el compartir tiene tanta fuerza como el egoísmo y es capaz de aportar a las organizaciones una potencialidad insospechada. 
Enfoques antropológicos

\begin{tabular}{lll}
\hline Modelo de organización & $\begin{array}{l}\text { Institución } \\
\text { Propósito }\end{array}$ & De servicio \\
\hline Concepto de persona & $\begin{array}{l}\text { Ser personal } \\
\text { Racionalidad }\end{array}$ & Instrumental, expresiva y práctica \\
& Motivaciones & Extrínsecas e intrínsecas y trascendentes \\
& Valores & De desarrollo personal y alteridad \\
& Normas & Principios \\
\hline Enfoque ético & Integral & Realista \\
& (Bienes, normas & \\
& y virtudes) & \\
\hline
\end{tabular}

Por otra parte, el enfoque antropológico ya no entiende las normas como unos mínimos restrictivos a la actuación, de origen subjetivo, o aceptadas socialmente, sino que estas adquieren el sentido de principios que rigen y orientan el obrar humano, favoreciendo con su presencia la libertad del individuo. Es preciso en este punto advertir sobre:

... la tendencia del manager a establecer principios con un procedimiento análogo al que se sigue para el establecimiento de objetivos. Los objetivos pueden establecerse; en cambio, los principios, los verdaderos principios, están ya naturalmente establecidos. La función del director es, en el mejor caso, el descubrirlos, explicitarlos y ponerlos en vigencia [...]. El aceptar cuáles son esos principios es el punto de partida de toda estrategia concebida en sus más elementales dimensiones éticas (Llano, 1990: 18-24).

El modelo antropológico sustituye la satisfacción de las necesidades por la elección en razón de los fines, y de este modo pone de relieve la existencia de una condición humana, de una «naturaleza» propia y distinta a la de aquellos seres que se mueven exclusivamente por impulsos.
El discernimiento de esta condición humana:

... conlleva el descubrimiento de la tarea que el hombre debe cumplir como ser específicamente dotado. Sin naturaleza humana, aparece sólo el concepto de tendencia y desaparece el concepto de deber para quedar sustituido insuficientemente por una ambigua sensación de plenitud, y no por un objetivo cumplimiento» (Llano, 1990: 46).

La felicidad no se alcanza en la cosa sino en la acción, en el obrar bien, porque el hacer bien las cosas es un fin en sí mismo y, de este modo, objeto de deseo por parte de la voluntad.

En el fondo el enfoque antropológico o humanista, sin desechar lo positivo de los modelos anteriormente explicados, intenta superarlos al tener una visión más completa de la persona y entiende a la organización como una institución cuya finalidad es conseguir la unidad e identificación de sus miembros con ella y sus objetivos. Así, los valores adquieren un sentido práctico y operativo. En un contexto como el descrito, no basta con la capacidad proactiva, propia del modelo 
organicista; el cumplimiento de las metas para todo evento no es lo principal, se trata de ocuparse en el cómo y para qué se logran, de modo que los valores declarados se desarrollen y vivan en la práctica: importa conseguir que los colaboradores asuman su trabajo como una misión compartida y no como un mero reto individual. Por consiguiente, la persona pasa a formar parte de un equipo y del comportamiento que tenga dependerá el resultado de la organización. Esta nueva competencia, la capacidad de cooperación, es algo más que la capacidad proactiva, porque ahora el individuo no se queda encerrado en sus propios objetivos: no sólo se trata de hacerlo bien para sobresalir, sino que se debe tener en cuenta a los demás.

Los tres modelos presentados no hay que entenderlos como excluyentes entre sí, sino cada uno como integrado y superado del anterior: el modelo psico-sociológico asume el modelo mecanicista; y el modelo antropológico, a su vez, integra los otros dos, en una visión más completa de la organización y de la persona. Se ha visto cómo cada uno de ellos reclama una presencia distinta de la ética, desde los enfoques unilaterales que tienen cabida en el modelo mecanicista hasta la visión integral de la ética que requiere el modelo antropológico.

\section{Conclusión}

La distinción que hemos utilizado entre «trabajo en sentido objetivo»y «trabajo en sentido subjetivo», para entender primariamente la emergencia de estos enfoques de la organización y posteriormente el carácter integrador del enfoque antropológico, es crucial. El trabajo, constitutivamente, es acción dominativa por par- te del individuo que lo realiza. Precisamente el carácter de dominio era lo que se señalaba como aporte del modelo antropológico al hablar de las satisfacciones reales, frente a los modelos anteriores. Mediante el dominio, el hombre transforma el mundo que lo rodea, no se queda en una mera adaptación al entorno, como resaltan algunos modelos de los enfoques psico-sociológicos, y lo hace servir a finalidades que él mismo persigue. Además, en el modelo antropológico se destacaba la capacidad ilimitada del hombre para adquirir nuevos aprendizajes, positivos o negativos; dicha capacidad da origen a un proceso acumulativo, en virtud del cual el dominio sobre la naturaleza es creciente y la perfección que el hombre puede adquirir es ilimitada. De este modo, el «trabajo en sentido objetivo» no se independiza del hombre, sino que es dependiente de él, en la medida en que se objetiva en realizaciones concretas llevadas a cabo por el empresario. El hombre se sitúa al principio y al final de ese trabajo. El enfoque antropológico resalta, como superación del dualismo presente en los otros dos enfoques, que el «trabajo en sentido objetivo» se ordena al «trabajo en sentido subjetivo», perfeccionando al empresario que lleva a cabo esa labor.

Sin embargo, la ordenación no se lleva a cabo de modo inmediato. Habrá que tener en cuenta cómo el hombre se comprende a sí mismo y cómo actúa. A lo largo del trabajo se ha visto que puede haber tensión entre ambos, e incluso ruptura. Pero esta situación no plantea problemas irresolubles; todo dependerá del modo cómo el hombre se comprenda a sí mismo y entienda su acción. En la distinción entre trabajo objetivo y subjetivo puede verse que «técnica y ética se nos presentan como dos realidades -más exactamen- 
te, como dos dimensiones de una misma realidad-distintas entre sí, pero no opuestas ni heterogéneas; antes al contrario llamadas a una íntima compenetración» (Illanes, 1994: 597).

En el trabajo que lleva a cabo el empresario se percibe claramente esa única realidad, en la medida en que los problemas sociales de las organizaciones son siempre, en última instancia, problemas del empresario. La técnica versa sobre los medios, mientras que la ética versa sobre los bienes y los fines, por lo que ha de ser la ética la que tenga en última instancia la palabra, evitando de este modo el posible conflicto que pudiera surgir entre ambas. Esta visión se contrapone a la posición de Weber (1992), para quien:
... la ciencia no da una respuesta a la cuestión básica de qué debemos hacer y cómo debemos organizar nuestra vida; esto sería función de un profeta o de un Mesías, no del científico, no del profesor.

El enfoque antropológico otorga una visión unitaria y comprensiva de la realidad. La postura antiética -bien sea antecedente o consecuente- en la que se encuentra situado el empresario moderno se supera a través de un enfoque antropológico. Es más, sin este enfoque el trabajo se quedaría en un mero sentido objetivo, perdiendo su sentido subjetivo y careciendo de ese aspecto que lo dignifica: el ser medio de perfección para quien lo lleva a cabo.

\section{Referencias bibliográficas}

ANSCOMBE, G. E. 1958. Modern moral philosophy. Philosophy. $\mathrm{N}^{\circ} 33$.

1981. Collected Philosophycal Papers. Vol. III, págs. 26-42. Oxford: Basil Blackuell.

CHANDLER, A. D. 1962. Strategy and structure: Chapters in the history of the american industrial enterprise. Cambridge: MIT Press.

CORTINA, A. 1994. Ética de la empresa. Madrid: Trotta.

1995. Ética de la sociedad civil. Madrid: Anaya.

CYERT, R. M. y MARCH, J. G. 1963. A behavioral theory of the firm. Englewood Cliffs (New Jersey): Prentice-Hall.
DURKHEIM, E. 1984. Collective and corporate responsability. New York: Columbia University Press.

ETZIONI, A. (ed.) 1995. New communitarian thinking: persons, virtues, institutions, and comunities. Charlotesville: University Press of Virginia.

FAYOL, H. 1949. General and industrial management. Reed, London: Isaac Putman \& Sons.

FONTRODONA,J.; GUILLÉN, M. y RODRÍGUEZ, A. 1998. La ética que necesita la empresa. Madrid: Unión Editorial.

GALBRAITH, J. 1973. Designing complex organizations. Reading: Addison-Wesley. 
HANNAN, M. T. y FREEMAN, J. H. 1989. Organizational ecology. Cambridge: Harvard University Press.

HAX, A. C. y MAJLUF, N. S. 1984. Strategic management: an integrative perspective. Englewood Cliffs (New Jersey): PrenticeHall.

HERZBERG, F. 1966. Work and the nature of man. New York.

HERZBERG, F.; MAUSNER, B y SNYDERMAN, B. The motivation to work. New York: Wiley.

ILLANES, J. L. 1994. El mercado: ética y eficiencia. En: D. Melé (ed.). Ética, mercado y negocios. Pamplona: Eunsa.

KOSLOWSKI, P. 1983. Mechanistiche und organistische: Analogien in der Wirtschaftswissenschaft -eine verfehlte Altemative. Kiklos. ․․ 36, págs. 308-312.

LAWRENCE, R. y LORSCH, J. W. 1967. Organization and environment. Homewood: Richard D. lrwin, Inc. [Existe una traducción al español: Organización y ambiente. Barcelona: Labor, 1973].

LIKERT, R. 1961. New patterns of management. New York: McGraw-Hill.

1967. The human organization. New York: McGraw-Hill.

LLANO, C. 1990. El empresario ante la motivación y la responsabilidad. México: McGraw-Hill.

1991. El empresario y su acción. México: McGraw-Hill.
LORSCH, J. W. y ALLEN, S. 1973. Managing diversity and interdependence. Cambridge: Harvard University Press.

MacINTYRE, A. 1992. Tres versiones rivales de la ética. Madrid: Rialp.

MARCH, J. y SIMNO, H. A. 1958. Organizations. New York: Wiley and Sons [Citado por la ed. de 1993. Cambridge: Blachwell].

MASLOW, A. H. 1991. Motivación y personalidad. Díaz de Santos. [Título original Motivation and personality. New York: Harper \& Brothers, 1954].

MAYO, E. 1946. The human problems of an industrial civilization. Cambridge: Harvard University Press [Original de 1933].

McGREGOR, D. 1960. The human side of enterprise. New York: McGraw-Hill.

1966. Leadership and motivation. Cambridge: The MIT Press.

MELE, D. 1997. Actuación social en la empresa. En: La aportación de la empresa a la sociedad. Barcelona: Folio.

MILLER, D. 1990. The icarus paradox. New York: Harper Business.

MILLER, D. y FRIESEN, P. H. 1984. Organizations: A quantum approach. Englewood Cliffs: Prentice-Hall.

MINTZBERG, H. 1979. The structure of organizations. Engewood Cliffs: Prentice-Hall.

NELSON, R. y WINTER, S. 1982. An evolutionary theory of economic change. Cambridge: Harvard University Press. 
PÉREZ LÓPEZ, J. A. 1994. Fundamentos de la dirección de empresas. Madrid: Rialp. 1997. Liderazgo. Barcelona: Folio.

POLO BARRENA, L. 1993. Presente y futuro del hombre. Madrid: Rialp.

RAWLS, J. 1971. A theory of justice. Cambridge, Mass.

ROBERTSON, D. C. y NICHOLSON, N. 1996. Expressions of corporate social responsability in U.K. firms. Journal of Business Ethics. N. ${ }^{\circ} 15$, págs. 1095-1106.

RODRÍGUEZ, A. y LÓPEZ DE PEDRO, J. M. 1998. El concepto de necesidad en la prestación de servicios. En: D. Melé (coord.). Ética en dirección comercial y publicidad. Pamplona: Eunsa, págs. 103-116.

RODRÍGUEZ, A. 1999a. La lógica originaria del emprendedor. Barcelona: IESE. Documento de investigación.

1999b. Una teoría del emprendedor: ensayo de la genealogía de un concepto. Barcelona: IESE. Tesis doctoral, no publicada.

ROETHLISBERGER, F. J. y DICKSON, W. J. 1939. Management and the worker. Cambridge: Harvard University Press.
SCHUMPETER, J. A. 1971. Capitalismo, socialismo y democracia. Madrid: Aguilar.

SEN, A. 1979. Utilitarianism and welfarism. The Journal of Philosophy. N. ${ }^{\circ} 76$, págs. 464-465.

SIMON, H. A. 1979. Rational decision making in business organizations. American Economic Review. N. ${ }^{\circ}$ 69, págs. 493-513.

TAYLOR, F. W. 1911. The principies of scientific management. New York: Harper.

WEBER, M. 1944. Economía y sociedad. México: Fondo de Cultura Económica. 1947. The theory of social and economic organization. Free Press.

1992. La ciencia como profesión; la política como profesión. Madrid: Espasa Calpe.

1995. La ética protestante y el espíritu del capitalismo. Barcelona: Península. 